\title{
Grupos empresariales familiares: cambios económicos y políticos en El Salvador
}

\author{
Family Business Groups: Economic and \\ Political Changes in El Salvador
}

\author{
Lissette Cristalina Canales \\ Facultad de Ciencias Empresariales \\ Universidad Tecnológica de El Salvador, El Salvador \\ https://orcid.org/0000-0002-6881-9245 \\ lissette.canales@utec.edu.sv
}

\section{RESUMEN}

Este artículo presenta de manera muy generalizada parte de la historia empresarial de 21 grupos empresariales familiares salvadoreños (GEFS), exponiendo características básicas como edad de operación, generación actual al mando, sector económico donde iniciaron operaciones, período aproximado en el que se considera se consolidaron como grupo empresarial y sectores en los que están diversificados. De igual manera, se exponen acontecimientos que han afectado positiva o negativamente la relación de estos grupos empresariales con el poder político, así como algunos detalles del financiamiento a partidos políticos.

Palabras clave: grupo empresarial familiar, diversificación, internacionalización, partido político, poder económico, historia económica.

Códigos JEL: D21, F23, L20. 


\section{ABSTRACT}

This article presents an overview of part of the business history of 21 Salvadorian family business groups, informing basic characteristics such as time of operation, current generation in charge, original economic sector where they started operations, approximate period where they consolidated as a business group, and sectors in which they have diversified over the years. Similarly, events that have positively or negatively affected the relationship of these groups with political powers are presented, as well as some details about the financing given to local political parties.

Keywords: Family business group, diversification, internationalization, political party, economic power, economic history.

JEL Codes: D21, F23, L20.

\section{INTRODUCCIÓN}

Los grupos empresariales familiares (GEF) son un tipo de organización empresarial común y de amplia influencia en los ámbitos políticos y económicos en la mayoría de países de América Latina. Sus orígenes, formas de organización y estrategias de sostenibilidad son temas de amplia discusión entre la comunidad académica (Bull et al., 2014; Cerutti, 2018; Chudnovsky \& López, 1998; Fernández \& Lluch, 2015;Vanoni-Martínez \& RodríguezRomero, 2017; Geymonat, 2020; Rodriguez-Satizabal, 2020).

Dentro de los estudios realizados existe evidencia de que en varios países el origen del poderío económico y político de algunas de las familias asociadas a estos grupos parte, en general, de emprendimientos familiares relacionados con una base agrícola, desarrollados durante las primeras décadas posteriores a la independencia. Del mismo modo, la consolidación de dichos grupos empresariales sucedió décadas después y su expansión comercial fue llevada a cabo por las siguientes generaciones, como en los casos de las familias Dueñas y Regalado, en El Salvador, o la familia Castillo, en Guatemala (Browning, 1998; Bull et al., 2014; Colindres,1977; Díaz, 2016; Llorca-Jaña et al., 2017). Adicionalmente, conforme se desarrollaban las economías locales, a estas familias se fueron agregando extranjeros por la vía del matrimonio, o inclusive otras familias de extranjeros ya conformadas, las cuales se establecieron en las primeras décadas republicanas en los respectivos países (Cerutti, 2006, citado en Dávila et al., 2021). 
Como evidencia de lo anterior, en Latinoamérica pueden encontrarse grupos empresariales familiares con gran influencia en la política y la economía, en los cuales se destacan ciertas nacionalidades en mayor o menor medida en cada uno de los países. Por ejemplo, mientras en El Salvador predominan los GEF fundados por inmigrantes españoles, en Honduras sobresalen los fundados por inmigantes árabes y palestinos (Amaya, 1995; Waxenecker, 2019).

En cuanto a la consolidación de los GEF en Latinoamérica, podría decirse que se debe a diversas razones, entre ellas a que varios de estos grupos (no todos) se desarrollaron bajo protecciones políticas en forma de monopolios, u oligopolios, y deficiencias institucionales. Específicamente, en El Salvador pueden mencionarse, entre otras, la ambigüedad y la falta de transparencia para la concesión de recursos públicos, la ausencia de leyes que regularan ciertas actividades comerciales o la carencia de instituciones que supervisaran las reglas de competencia. El crecimiento de los GEF fue también posible gracias a los cambios generados por programas de ajuste estructural realizados a finales de los años ochenta del siglo pasado, acompañados de procesos de privatización, que en algunos países fueron más agresivos (El Salvador, Honduras y Guatemala) que en otros (Costa Rica y Uruguay). Por otro lado, se experimentaron cambios hacia una mayor apertura de las economías a través del establecimiento de la Unión Aduanera en 1960, los acuerdos comerciales desde los años noventa y los diferentes tratados de libre comercio (TLC), tanto bilaterales como multilaterales (Arias, 2010; Bull, 2013; Cerruti, 2018; Geymonat, 2020; Segovia, 2005).

Esta apertura de la economía y la presencia de más extranjeros siempre en el caso específico de El Salvador - atrajo, como ha sido ampliamente ventilado entre la comunidad académica, a la banca transnacional, la cual influyó en los GEF locales que ya vivían una mayor competencia en el mercado local (Arias, 2010; Cabrera, 2015; Robles, 2014; Segovia, 2005). Para unos, la influencia fue positiva en el sentido de una mayor oferta de financiamiento y de acceso a otros servicios financieros, pero para los que poseían inversiones en el sector financiero resultó ser un punto de inflexión en el que, aparentemente, solo quedaban dos opciones: la primera, asociarse con los nuevos jugadores, en el caso que eso fuese posible, y la segunda, vender a los bancos internacionales. Un detalle en mayor profundidad sobre esta serie de cambios, así como sobre la forma en la que han influido, 
organizado y operado los grupos empresariales familiares en El Salvador se encontrará a lo largo de este documento.

A nivel local, El Salvador ha sido conocido como el país de las catorce familias, lo cual no significa que el país continúe siendo dominado únicamente por estas familias, ya que, de hecho, Albiac (1998, citado en Waxenecker, 2017) hace un planteamiento sobre el cambio de 14 a 116 personas o grupos familiares con predominante influencia a partir de las transformaciones económicas de finales del siglo XX. Pese a que no existe un consenso entre los diversos autores de quiénes conforman o son específicamente esas catorce familias, los autores que han escrito sobre ellas han identificado desde finales del siglo XIX apellidos que se mantienen pujantes en la economía, como pueden ser los Álvarez, Guirola, De Sola, Dueñas, Regalado, Palomo, Murray, Sol, Quiñonez, García Prieto, Cristiani, Hill, Quirós, Kriete, Poma y otros (Albiac, 1998; Arias, 2010; Browning, 1998; Colindres, 1977; Paniagua, 2002; Segovia, 2005; Martínez-Peñate, 2017; Waxenecker, 2017). Algunos de estos apellidos, como Kriete, Murray y Poma, son también reconocidos por las principales revistas de negocios de la región como exitosos líderes de grupos empresariales expandidos a lo largo del territorio centroamericano.

\section{OBJETIVOS, METODOLOGÍA Y ALCANCES}

Dentro de sus objetivos, este documento busca exponer a grandes rasgos parte de la historia empresarial de 21 grupos empresariales salvadoreños, así como la vinculación de algunos de ellos con la banca y la política. La información presentada forma parte de los datos recolectados en un estudio de empresas familiares realizado entre 2017 y 2020, cuya muestra especificaba, entre otras características, tener su origen en empresas fundadas en El Salvador, ser de alto reconocimiento en el mercado salvadoreño, contar con participación de al menos un miembro de la familia fundadora y, finalmente, tener la categoría tributaria de mediana o gran empresa. Para recolectar la información se recurrió a investigación documental en diversas fuentes, tales como el Centro Nacional de Registros (CNR), el Diario Oficial, el Ministerio de Hacienda, el Instituto Salvadoreño del Seguro Social, la Secretaría de Transparencia y Anticorrupción, periódicos digitales, sitios web corporativos, revistas de negocios y memorias de labores corporativas y gremiales, entre otros. 
Como aportes específicos, este documento brinda la posibilidad de tener una aproximación más cercana y precisa sobre las circunstancias de los GEF del país. Se pretende así mismo exponer algunos detalles sobre el financimiento a los partidos políticos por parte de estos grupos entre 2006 y 2017, datos que hasta 2019 eran de índole privada, y desconocidos por tanto para cualquier persona que se interesara en el tema. Finalmente, una contribución relevante viene dada por la oportunidad de disponer para el análisis y la discusión de la comunidad académica de información reciente y hasta cierto punto comparable con la que ya existe de los países centroamericanos vecinos o de otros países latinoamericanos.

\section{GRUPOS EMPRESARIALES FAMILIARES Y GRUPOS EMPRESARIALES SALVADOREÑOS (GEFS)}

La discusión sobre los grupos empresariales en cuanto a su organización, ventajas y desventajas ha incrementado en diversas partes del mundo, y las reflexiones sobre este tipo de organización empresarial exponen diferencias con respecto a su relevancia, caracterización y formas de gestión (Cainelli \& lacobucci, 2011). En América Latina, y sobre todo en aquellos países con bolsas de valores incipientes, ha sido un reto poder acceder desde una fuente oficial a la información de los grupos empresariales, más si se trata de los que son familiares, dado que las leyes no incluyen que se lleven registros de grupos empresariales como tal, aunque en algunos países como México y Colombia se han hecho intentos y avances en este tema (Cerutti, 2018; Geymonat, 2020; Rodriguez-Satizabal, 2020).

En un sentido muy amplio, los grupos empresariales pueden caracterizarse por ser un mecanismo económico de organización en el cual compañías legalmente independientes se hacen de acuerdos colaborativos para la mejora de su bienestar. Al respecto, se ha encontrado evidencia que tanto en los países desarrollados como en los menos desarrollados los propietarios de estos grupos suelen ser el Estado, algunas familias y los bancos (Colpan et al., 2010). Existen también distinciones de organización, pero las formas más comunes suelen ubicarse entre la estructura piramidal y la de grupos conjuntos u horizontales. Revisando más a fondo la relación de los grupos empresariales con la economía, Schneider (2009) encuentra particularidades en estos tanto por el tipo de economías en las que operan como por la forma en la que se han desarrollado en los mercados. En particular, 
Schneider (citado en Robles, 2014) enfatiza que en el capitalismo latinoamericano pueden encontrarse lo que él denomina "economías jerarquicas de mercado", que son economías caracterizadas por grupos de empresas diversificadas, activas al mismo tiempo en cuatro o cinco sectores, y en las que existe control jerárquico familiar a través de participaciones significativas $u$ otras conexiones financieras.

Por otro lado, la definición y las características de lo que es un GEF han sido ampliamente discutidas. Varios autores tienden a identificar como tal a aquel en el que se distingue la participación parcial o total de la familia o familias interrelacionadas en la propiedad de varias empresas, jurídicamente independientes, y en las que se controla estratégicamente la dirección (Bru \& Crespí, 2008; Bull et al., 2014; Cainelli \& lacobucci, 2011; Colmenares, 1977; Fernández \& Lluch, 2015; Khanna \& Yafeh, 2007).

Un punto importante por aclarar es que ambos títulos han sido utilizados para referirse a los grupos económicos predominantes en cada país, es decir, tanto a los grupos empresariales (Rodriguez-Satizabal, 2020) como a los GEF. Puede decirse también que su denominación ha variado dependiendo del momento histórico, del país y del sector económico en donde se realiza el estudio, y que otros ejemplos de denominaciones para estos grupos de poder económico son burguesías (Colindres, 1977), bloques hegemónicos (Paniagua, 2002), grupos de poder (Segovia, 2005), grupos empresariales diversificados (Bull et al., 2014), élites políticas y económicas (Waxenecker, 2017), élites (Robles, 2017) y grupos industriales empresariales (Geymonat, 2020).

Ahora bien, en el estudio de la vinculación de familias con actividades y entidades económicas particulares en El Salvador se identifican pioneros como Colindres (1977), Browning (1998) y Paniagua (2002), y bajo una aproximación más moderna a Segovia (2005), Arias (2010), Robles (2017), Martínez-Peñate (2017) y Waxenecker (2017). Este último autor plantea la vinculación del poder económico con el poder político y la forma como esa relación permitió, en sus propias palabras, "que las transformaciones fundamentales del modelo económico vigente se fraguaran en un entorno de influencia privilegiada de las élites sobre la toma de decisiones institucionales durante la década de 1990" (Waxenecker, 2017, p. 62). A través de un análisis de la gran empresa salvadoreña a partir de las interrelaciones entre integrantes de estructuras directivas y gerenciales en 2011, este autor también se vale del concepto de captura del Estado para explicar el poder que sobre 
los funcionarios políticos, las políticas económicas y las instituciones tienen un número limitado de familias.

Las vinculaciones entre estas pocas familias y los grupos empresariales familiares constituyen un patrón común en América Latina. De hecho, existen entre algunos países denominadores comunes, como el hecho de ser economías con élites de base agraria, una continuidad de estas élites - que en algunos países fue mucho más corta que en otros-, así como una connotada vinculación con el poder político (Barahona, 2019; Cuadra, 2016; Díaz, 2016; Serna \& Bottinelli, 2018). También existe similitud en el surgimiento de una nueva élite a partir de los procesos de industrialización después de los años sesenta y de las reformas estructurales de finales de los años ochenta del siglo pasado (Bull, 2013; Cerutti, 2018; Dávila et al., 2021; Geymonat, 2020).

Para comprender el origen y la situación actual de los GEFS que se presentan en este documento, es necesario primero considerar la historia sociopolítica y económica del país, dentro de la cual pueden identificarse claramente cinco grandes períodos: la Colonia (1524-1821), la post Independencia con gobiernos civiles intermitentes (1821-1928), los gobiernos militares (1928-1980), la guerra civil (1979-1989) y la democracia (1992 a la fecha). Durante el segundo período de post Independencia se sitúa el origen de las actividades de influencia política y económica de las familias Álvarez, Dueñas y Regalado, hoy vinculadas también a familias propietarias de Grupo Agrisal, Grupo Cassa, Grupo Poma y Grupo Kriete. El cultivo, procesamiento y exportación de café fue lo que permitió a estas familias, y a otras que conformaban esta élite agroindustrial, acumular el suficiente capital para posteriormente expandirse a otros sectores. En ese período también se establecieron (o iniciaron) en el país, con sus actividades económicas, familias extranjeras que, como se aprecia en la tabla 1, no se arraigaron en la agroindustria sino en otros sectores. Si bien en un inicio estas familias extranjeras no formaron parte de la élite local, poco a poco fueron creciendo empresarialmente, vinculándose con las anteriores u otras que estaban ya establecidas en el país, de manera muy similar a lo sucedido en otros países de Latinoamérica (Cerutti, 2006, citado en Dávila et al., 2021).

Con el pasar del tiempo, familias como los Guirola, Dueñas, Regalado, Álvarez, Escalante Arce, Sol Millet, Borja, Natán y Alfaro hacían parte de las instituciones financieras y controlaban no solo la política y la tenencia de la tierra sino también el financiamiento, a través de las juntas directivas 
de los bancos (tabla 2), situación que se extendió hasta 1979. El fin de los años setenta anunciaba el inicio de una década tormentosa para el país, dado que existió en esos años un conflicto político y una profunda crisis interna que afectaba al gobierno de la Junta Militar demócrata-cristiana (Martinez-Peñate, 2013).

En medio de todo ese conflicto político y social, el gobierno adoptó la medida de nacionalizar la banca, con el afán de evitar el conflicto armado que finalmente terminó estallando. La estatización de la banca significó un duro golpe para estas familias, pues de acuerdo con la Ley de Nacionalización de las Instituciones de Crédito, los antiguos propietarios dispondrían de un $29 \%$ de las acciones de los bancos y ningún grupo económico, ninguna familia, o accionista a título personal podría participar en más de un banco (Banco Central de Reserva de El Salvador, BCR, 2021a). A mediados de los años ochenta, los indicadores por los que se habían nacionalizado los bancos retrocedieron a niveles inferiores a los que tenían antes de la nacionalización. En 1989 ganó las elecciones presidenciales el candidato Alfredo Cristiani, representante del partido de pensamiento derechista Alianza Republicana Nacionalista (ARENA). ${ }^{1}$ El siguiente año, el nuevo gobierno aprobó la Ley de Saneamiento y Fortalecimiento de Bancos Comerciales y Asociaciones de Ahorro y Préstamo, considerando que le correspondía al Estado asumir la responsabilidad del saneamiento de dichas instituciones financieras, para garantizar la sanidad de su cartera, en preparación de la reprivatización de estas (Banco Central de Reserva de El Salvador, 2021a).

Así, entre 1991 y 1994 se vendieron las acciones de las instituciones financieras propiedad del Estado a accionistas particulares, quedando nuevamente las instituciones en manos privadas, que en algunos de los casos fueron las mismas familias vinculadas antes de la nacionalización de 1979, con la diferencia de que ahora ya no eran solo familias cafetaleras, sino que también se habían incorporado otras de una nueva élite empresarial como los Freund, Simán, Poma, Salume y Bahaia (Secretaría de Participación, Transparencia y Anticorrupción, 2019). Este último proceso fue muy criticado y se acusó de haber privatizado la banca a través de decretos que permitían que los mismos bancos financiaran la deuda de los que compraban las acciones; el punto más reprochado fue que después de la privatización la familia del expresidente Cristiani resultó siendo accionista del Banco

Este partido había sido fundado por el militar mayor Roberto D'Abuisson, representando desde sus orígenes los intereses de empresarios y miembros de la élite cafetalera. 
Cuscatlán² (Arias, 2010). Otra fuerte crítica es que este proceso de venta al capital extranjero no pagó un aproximado de 260 millones de dólares en concepto de impuestos (IVA y renta), que terminaron como elusión fiscal, debido a incentivos de parte del gobierno y a que las leyes de aquel momento no lo permitían. En 2009, a petición del Ministerio de Hacienda, la Asamblea Legislativa modificó la ley para que a partir de aquel momento ese tipo de transacciones estuviese sujeto al pago del ISR (Secretaría de Participación, Transparencia y Anticorrupción, 2019).

A partir de 2001 los bancos del país iniciaron un proceso de regionalización, lo que vino después a ser impulsado por la firma del TLC entre República Dominicana, Estados Unidos y Centroamérica. Entre 2005 y 2009, todos los bancos de capital salvadoreño habían sido adquiridos por capital internacional, y los salvadoreños que aún formaban parte de estos tenían una participación muy pequeña, representando $1,1 \%$, de acuerdo a la nacionalidad del accionista principal de la compañía controladora. La venta de los bancos significó para los GEFS vinculados una inyección importante de capital para consolidar sus operaciones a nivel nacional e internacional.

Tabla 1. Principales características de los GEFS

\begin{tabular}{|c|c|c|c|c|c|c|c|c|c|c|}
\hline N. ${ }^{\circ}$ & $\begin{array}{l}\text { Nombre del } \\
\text { GEF }\end{array}$ & Familia & $\begin{array}{l}\text { Años de } \\
\text { operación } \\
\text { empresa- } \\
\text { rial de la } \\
\text { familia }\end{array}$ & $\begin{array}{l}\text { Generación } \\
\text { al mando }\end{array}$ & $\begin{array}{l}\text { Origen del } \\
\text { fundador }\end{array}$ & $\begin{array}{c}\text { Nivel de } \\
\text { diversifica- } \\
\text { ción }\end{array}$ & $\begin{array}{l}\text { Tamaño de } \\
\text { contribu- } \\
\text { yente de } \\
\text { acuerdo a } \\
\text { Hacienda }\end{array}$ & $\begin{array}{l}\text { Número } \\
\text { de } \\
\text { emplea- } \\
\text { dos }\end{array}$ & $\begin{array}{l}\text { Fundación } \\
\text { vinculada }\end{array}$ & Industria \\
\hline 1 & $\begin{array}{l}\text { Grupo Calleja } \\
\text { (Super Selectos) }\end{array}$ & Calleja & 68 & Segunda & $\begin{array}{c}\text { Salvadoreño, } \\
\text { ascendencia } \\
\text { española }\end{array}$ & Medio & Grande & 600 & $\begin{array}{l}\text { Fundación } \\
\text { Calleja }\end{array}$ & Retail, comercio detallista \\
\hline 2 & $\begin{array}{l}\text { Grupo Samix, } \\
\text { S.A. de C.V. }\end{array}$ & Saca Mixco & 26 & $\begin{array}{l}\text { Primera y Se- } \\
\text { gunda (CONAB) }\end{array}$ & $\begin{array}{c}\text { Salvadoreño, } \\
\text { ascendencia } \\
\text { palestina }\end{array}$ & Nulo & Mediana & 200 & $\mathrm{~N} / \mathrm{D}$ & Medios de comunicación \\
\hline 3 & Grupo CASSA & $\begin{array}{l}\text { Regalado } \\
\text { Dueñas }\end{array}$ & 54 & Cuarta & $\begin{array}{c}\text { Salvadoreña, } \\
\text { ascendencia } \\
\text { española }\end{array}$ & Alto & Grande & 10.500 & $\begin{array}{c}\text { Asociación } \\
\text { Ecológica Vista } \\
\text { al Valle }\end{array}$ & $\begin{array}{l}\text { Industria azucarera, } \\
\text { sector de energía }\end{array}$ \\
\hline 4 & Grupo Siman & Simán & 99 & Tercera & Palestina & Alto & Grande & 1.500 & $\begin{array}{l}\text { Fundación } \\
\text { Siman }\end{array}$ & $\begin{array}{l}\text { Retail, inmobiliario, } \\
\text { servicios financieros }\end{array}$ \\
\hline 5 & $\begin{array}{c}\text { Grupo Agrisal } \\
\text { (Hotel Crowne } \\
\text { Plaza) }\end{array}$ & Meza Ayau & 114 & Tercera & Guatemala & Alto & Grande & 5.000 & $\begin{array}{l}\text { Fundación } \\
\text { Meza Ayau }\end{array}$ & $\begin{array}{c}\text { Inmobiliaria, automotriz, } \\
\text { hotelera }\end{array}$ \\
\hline
\end{tabular}

2 Que había sido fundado en 1972 por Roberto Hill, nacionalizado en 1980 y posteriormente privatizado en 1993. 


\begin{tabular}{|c|c|c|c|c|c|c|c|c|c|c|}
\hline 6 & Grupo Poma & Poma & 102 & Tercera & $\begin{array}{l}\text { España (Barce- } \\
\text { Iona) }\end{array}$ & Alto & Grande & 10.000 & $\begin{array}{l}\text { Fundación } \\
\text { Poma }\end{array}$ & $\begin{array}{l}\text { Hotelera, inmobiliaria, indus- } \\
\text { trial, financiera, } \\
\text { automotriz }\end{array}$ \\
\hline 7 & Grupo Bolívar & De Sola & 124 & Tercera & $\begin{array}{c}\text { Antillas Holan- } \\
\text { desas }\end{array}$ & Alto & Grande & N/D & $\begin{array}{c}\text { Glasswing } \\
\text { Internacional }\end{array}$ & $\begin{array}{l}\text { Inmobiliaria, seguros y } \\
\text { agronegocios }\end{array}$ \\
\hline 8 & Grupo Q & Quirós & 68 & Segunda & El Salvador & Medio & Grande & N/D & No tienen & $\begin{array}{c}\text { Retail, financiamiento, bienes } \\
\text { raíces }\end{array}$ \\
\hline 9 & Grupo Cristiani & Cristiani & 89 & Tercera & Italia & Medio & Grande & N/D & $\begin{array}{l}\text { Fundación } \\
\text { Raíces }\end{array}$ & $\begin{array}{l}\text { Agroindustria, farmacéutica, } \\
\text { tecnología, servicios de } \\
\text { seguridad }\end{array}$ \\
\hline 10 & Grupo Salume & Salume & 59 & Segunda & $\begin{array}{c}\text { Salvadoreña, } \\
\text { ascendencia } \\
\text { Palestina }\end{array}$ & Alto & Grande & 3.000 & $\begin{array}{l}\text { Fundación } \\
\text { Nicolás Salume }\end{array}$ & $\begin{array}{c}\text { Alimentos, bienes raíces, } \\
\text { logística }\end{array}$ \\
\hline 11 & $\begin{array}{l}\text { Grupo Cam- } \\
\text { pestre }\end{array}$ & $\begin{array}{l}\text { Romero } \\
\text { Guzmán }\end{array}$ & 33 & Segunda & El Salvador & Alto & Grande & 1.600 & $N / D$ & $\begin{array}{l}\text { Alimentos, agronegocios, } \\
\text { hostelería, servicios }\end{array}$ \\
\hline 12 & Grupo Lorena & $\begin{array}{l}\text { Rodríguez } \\
\text { Angulo }\end{array}$ & 39 & Segunda & Segunda & Alto & Grande & 1.000 & $N / D$ & $\begin{array}{l}\text { Alimentos y bebidas, hotele- } \\
\text { ría, estaciones de servicio }\end{array}$ \\
\hline 13 & Grupo FASANI & Silhy & 55 & $\begin{array}{l}\text { Primera y } \\
\text { Segunda }\end{array}$ & $\begin{array}{l}\text { El Salvador. } \\
\text { ascendencia } \\
\text { Palestina }\end{array}$ & Media & Grande & 500 & Fundasani & $\begin{array}{l}\text { Farmacéutica, química-indus- } \\
\text { trial, inmobiliaria }\end{array}$ \\
\hline 14 & Grupo Vidrí & Vidrí & 101 & Segunda & $\begin{array}{l}\text { España (Cata- } \\
\text { luña) }\end{array}$ & Alto & Grande & 847 & N/D & $\begin{array}{c}\text { Ferretería, manufactura de } \\
\text { herramientas, distribución, } \\
\text { bienes raíces }\end{array}$ \\
\hline 15 & Grupo Freund & Freund & 107 & Tercera & $\begin{array}{l}\text { Alemania, } \\
\text { ascendencia } \\
\text { judía }\end{array}$ & Medio & Grande & 1.377 & $\begin{array}{c}\text { Fundación Max } \\
\text { Freund }\end{array}$ & $\begin{array}{l}\text { Ferretería, inmobiliaria, } \\
\text { manufactura de objetos de } \\
\text { aluminio }\end{array}$ \\
\hline 16 & $\begin{array}{c}\text { Grupo TCS } \\
\text { (Canales 2, } \\
4 \text { y } 6)\end{array}$ & Eserski & 35 & Segunda & Polonia & Bajo & Grande & $\mathrm{N} / \mathrm{D}$ & Fundación TCS & $\begin{array}{c}\text { Medios de comunicación en } \\
\text { TV y digitales (redes sociales } \\
\text { y apps) }\end{array}$ \\
\hline 17 & Grupo Safie & Safie & 57 & Primera & Palestina & Alto & Grande & N/D & $N / D$ & $\begin{array}{c}\text { Hotelería, telecomunicaciones, } \\
\text { medios de comunicación, } \\
\text { bienes raíces }\end{array}$ \\
\hline 18 & Grupo Kriete & Kriete & 57 & Tercera & Estados Unidos & Bajo & Grande & 2.482 & $\begin{array}{l}\text { Fundación Glo- } \\
\text { ria de Kriete }\end{array}$ & $\begin{array}{l}\text { Aerolíneas, servicios de } \\
\text { mantenimiento aeronáutico, } \\
\text { inmobiliaria }\end{array}$ \\
\hline 19 & Grupo Dutriz & Dutriz & 117 & Tercera & $\begin{array}{l}\text { Salvadoreña, } \\
\text { ascendencia } \\
\text { española }\end{array}$ & Bajo & Exentos & N/D & $N / D$ & $\begin{array}{l}\text { Medios de comunicación, } \\
\text { prensa, redes sociales, apps y } \\
\text { otros medios digitales }\end{array}$ \\
\hline 20 & Grupo Molina & Molina & 76 & Segunda & Salvadoreña & Bajo & Mediana & 200 & $N / D$ & Alimentos \\
\hline 21 & $\begin{array}{l}\text { Grupo Sala- } \\
\text { verría }\end{array}$ & Salaverría & 61 & $\begin{array}{l}\text { Segunda y } \\
\text { Tercera }\end{array}$ & Salvadoreña & Alto & Mediana & 800 & $\mathrm{~N} / \mathrm{D}$ & $\begin{array}{l}\text { Publicidad, agroindustria, au- } \\
\text { tomotores, finanzas, turismo, } \\
\text { logística, bienes raíces }\end{array}$ \\
\hline
\end{tabular}

Nota: considere los años como la edad aproximada de gestión empresarial de la familia. Revise la tabla 3 para identificar el período aproximado en el que los negocios familiares se consolidaron como Grupo Empresarial Familiar. 


\begin{tabular}{|c|c|}
\hline Paniagua (2002) & Segovia (2005) \\
\hline $\begin{array}{c}\text { Banco Agrícola Comercial: Baldochi Dueñas, Kriete Ávila, Palo- } \\
\text { mo Déneke, Araujo Eserki, Cohen, Schildkneckt, Red Familiar } \\
\text { Empresarial (RFE): Meza (Meza/Hill/Palomo, Meza/Quiñonez/ } \\
\text { Sol, Meza/Alvarez, Meza/Murray) }\end{array}$ & $\begin{array}{c}\text { Grupo Adoc: Familia Palomo Meza } \\
\text { Grupo Agrisal: Familia Meza Ayau }\end{array}$ \\
\hline $\begin{array}{c}\text { Grupo Banco Agrícola:Familias Baldocchi-Dueñas, } \\
\text { Kriete }\end{array}$ \\
\hline $\begin{array}{c}\text { Banco Salvadoreño: Simán: Simán Jacir, Simán de Bahaia, } \\
\text { Simán Dada, Salume }\end{array}$ & Grupo Cuscatlán: Familias Bahaia y Cristiani \\
\hline Banco de Comercio: Belismelis, Freund, Sol Millet & \\
\hline Banco de Desarrollo: Salaverría Borja & \\
\hline Banco Ahorromet Scotiabank: Salaverría Prieto, Quirós, Poma, \\
Llach Hill
\end{tabular}

Tabla 2. Principales familias y grupos empresariales salvadoreños relacionados con la banca identificados por diversos autores entre los años 2000 y 2010

Fuente: adaptado de Waxenecker (2017)

\section{CARACTERIZACIÓN, DESARROLLO Y DIVERSIFICACIÓN DE LOS GEFS}

La revisión de una pequeña parte de la historia política y de la vinculación de los GEFS con la banca brinda al lector una mejor aproximación a las fuentes de acumulación de poder económico y político, así como a algunos de los factores que han afectado su desempeño positiva o negativamente.

Ahora bien, en cuanto a la forma en la que operan actualmente, puede decirse que en su mayoría estos grupos son gestionados por la segunda y tercera generación de la familia, con un promedio de 73,4 años de operación y variaciones entre 26 y un máximo de 124 años (tabla 1). Destacan por su corta longevidad los grupos Samix, Lorena, Campestre y TCS, que en menos de cuarenta años se han consolidado como grupos empresariales nacionales. Es importante mencionar que de estos cuatro grupos de corta edad, dos han sido fundados por salvadoreños (Grupo Lorena y Grupo Campestre) sin cercana ascendencia extranjera, ambos en la zona oriental del país, asociados a la industria de alimentos en productos hasta cierto punto no transables, y ambos diversificados en sectores complementarios a la operación inicial de la familia fundadora.

Los GEFS más antiguos, Bolívar (De Sola), Poma, Siman y Freund, lograron consolidarse debido a que en el momento en que iniciaron sus negocios 
lo hicieron en sectores donde no existía una oferta consolidada de esos bienes o servicios, lo que les dio la oportunidad de tener las ventajas del pionero, así como aprovechar las deficiencias del mercado y sus regulaciones (tablas 1, 3 y 4). Estos grupos podrían considerarse como parte de los fundadores de la economía moderna de El Salvador, dirigentes empresariales que junto a otros actores políticos de la época establecieron las bases de competencia. Sus redes de contactos, capacidades técnicas, visión de mundo y recursos relativamente superiores a los de los empresarios locales se convirtieron, deliberadamente o no, en el aporte necesario a la sociedad y economía de la época para competir en un mundo más globalizado. Grupo Poma, por ejemplo, desarrolló habilidades y creó capacidades para la importación de vehículos y mecánica automotriz, mientras que Grupo De Sola sentó las bases y desarrolló los servicios logísticos, el comercio minorista y la industria inmobiliaria residencial, al ser los pioneros en desarrollar proyectos habitacionales a gran escala.

Los grupos Dutriz y Eserski desarrollaron los medios de comunicación impresos y de televisión, en los cuales se mantuvieron como actores dominantes por muchas décadas. El grupo Kriete desarrolló la industria de la aviación en el país y la región centroamericana, en medio del conflicto armado y posteriormente a este, y pese a que se desarrolló gracias a la necesidad de los salvadoreños de huir y posteriormente volver al país, su crecimiento permitió de manera paralela la creación de una industria de mantenimiento aeronáutico y de una carrera universitaria para formar profesionales en este servicio que pudieran brindar atención a empresas aeronáuticas a nivel mundial (UDB, 2021).

Tabla 3. Resumen de períodos en los que se consolidaron como tal los

\begin{tabular}{|c|c|c|}
\hline Período & Grupos & Sector/Sectores iniciales \\
\hline Entre 1921 y 1930 & Grupo Bolívar (De Sola) & $\begin{array}{c}\text { Importación y exportación de artículos de } \\
\text { primera necesidad. Servicios logísticos. }\end{array}$ \\
\hline Entre 1951 y 1960 & $\begin{array}{c}\text { Grupo Agrisal } \\
\text { Grupo Poma } \\
\text { Grupo Simán }\end{array}$ & $\begin{array}{c}\text { Servicios de mecánica automotriz, distribución } \\
\text { de vehículos. }\end{array}$ \\
& Grupo Freund & Retail (comercio minorista de ropa). \\
& Grupo Cristiani & Ferretería. \\
\hline Entre 1961 y 1970 & $\begin{array}{c}\text { Grupo Salume } \\
\text { Grupo TCS (Eserski) } \\
\text { Grupo Molina }\end{array}$ & Farmacéutica y agroindustria (café). \\
& Comercio minorista. \\
\hline
\end{tabular}




\begin{tabular}{|c|c|c|}
\hline Entre 1971 y 1980 & Grupo Calleja & Retail (supermercados). \\
& Grupo Salaverría & Agroindustria (café) y publicidad. \\
\hline \multirow{2}{*}{ Entre 1981 y 1990} & Grupo Samix & Radio. \\
& Grupo Vidrí & Ferretería. \\
Grupo Safie & Manufactura de textiles. \\
& Grupo Kriete & Transporte aéreo. \\
\hline Entre 1991 y 2000 & Grupo Quirós & Distribución de automotores. \\
& Grupo Campestre & Alimentos (pollo frito). \\
& Grupo Lorena & Alimentos (panadería). \\
\hline Grupo Fasani & Farmacéutica. \\
\hline Grupo Dutriz & Grupo Cassa & Agroindustria (procesamiento de azúcar). \\
\hline
\end{tabular}

\begin{tabular}{|c|c|c|c|}
\hline $\begin{array}{c}\text { Grupo empre- } \\
\text { sarial }\end{array}$ & $\begin{array}{c}\text { Nombre de la } \\
\text { empresa }\end{array}$ & $\begin{array}{c}\text { Situación en el } \\
\text { mercado }\end{array}$ & Cambios o efectos desde 2009 \\
\hline Grupo Kriete & TACA & $\begin{array}{l}\text { Posición dominante } \\
\text { debido a carencia de } \\
\text { regulaciones y contro- } \\
\text { les en la Ley Orgánica } \\
\text { de Aviación Civil y Ley } \\
\text { Orgánica de CEPA. }\end{array}$ & $\begin{array}{l}\text { Ingreso de competidores de menor costo como } \\
\text { Veca Airlines, Spirit, Interjet y Volaris (Kriete es } \\
\text { miembro fundador de Volaris). } \\
\text { Es necesario destacar que Veca era una empresa } \\
\text { del ALBA que ya cerró operaciones, y que Ro- } \\
\text { berto Kriete tiene participación de la mexicana } \\
\text { Volaris', como se menciona en la ficha del Grupo } \\
\text { Kriete. } \\
\text { Implementación de la Política de Cielos Abiertos. }\end{array}$ \\
\hline Grupo Salume & Molsa & $\begin{array}{l}\text { Oligopolio (Molsa y } \\
\text { Harisa). }\end{array}$ & $\begin{array}{l}\text { Sanciones millonarias de parte de la Superin- } \\
\text { tendencia de Competencia para los dos actores } \\
\text { económicos en cuestión. }\end{array}$ \\
\hline $\begin{array}{c}\text { Grupo Cristiani y } \\
\text { Fasani }\end{array}$ & $\begin{array}{l}\text { Droguería Santa } \\
\text { Lucía } \\
\text { Laboratorios } \\
\text { Suizos y Farmacia } \\
\text { San Nicolás }\end{array}$ & $\begin{array}{l}\text { Libertad para la fijación } \\
\text { de precios de los } \\
\text { medicamentos. }\end{array}$ & $\begin{array}{c}\text { Creación de la Ley de Medicamentos de 2012, } \\
\text { que establecía techos a los precios, así como ma- } \\
\text { yor control a través de la creación de la Dirección } \\
\text { Nacional de Medicamentos. }\end{array}$ \\
\hline $\begin{array}{l}\text { Grupo Eserski y } \\
\text { Grupo SAMIX }\end{array}$ & $\begin{array}{l}\text { Telecorporación } \\
\text { salvadoreña (TCS) }\end{array}$ & $\begin{array}{l}\text { Posición dominante } \\
\text { debido a carencia } \\
\text { de regulaciones y } \\
\text { controles en la Ley de } \\
\text { Telecomunicaciones. }\end{array}$ & $\begin{array}{l}\text { Reformas a la Ley de Telecomunicaciones de } \\
2017 \text { y } 2019 \text {, que entre otras pretendía endure- } \\
\text { cer la regulación y mejorar los mecanismos para } \\
\text { el otorgamiento de señales y frecuencias. }\end{array}$ \\
\hline $\begin{array}{l}\text { Grupo Poma y } \\
\text { Grupo Quirós }\end{array}$ & $\begin{array}{l}\text { Didea } \\
\text { Grupo } 0\end{array}$ & $\begin{array}{l}\text { Durante muchos años } \\
\text { funcionaron como } \\
\text { un oligopolio en la } \\
\text { comercialización de } \\
\text { vehículos nuevos e in- } \\
\text { fluenciaron las políticas } \\
\text { para la importación de } \\
\text { vehículos usados. }\end{array}$ & $\begin{array}{l}\text { Las regulaciones a la importación de vehículos } \\
\text { usados abrieron una ventana para una mayor } \\
\text { competencia en el sector (Decreto } 383 \text { y sus re- } \\
\text { formas). Desde } 2017 \text {, se discuten propuestas de } \\
\text { Ley para disminuir los años para la importación } \\
\text { de vehículos usados. }{ }^{4}\end{array}$ \\
\hline
\end{tabular}

Nota: se toma como año de referencia el año aproximado en el que cada grupo empresarial inició operaciones con otra operación, para lo que creó otra u otras empresas dirigidas por la misma familia. Por cuestiones de espacio, en este artículo no se puede presentar toda la historia de cada grupo empresarial.

Fuente: elaboración propia.

Tabla 4. GEF que crecieron a la sombra de fallas de mercado y deficiencias de institucionalidad

3 Vuela El Salvador, S.A. de C.V. es la subsidiaria de Volaris en El Salvador.

4 La principal promotora de las reformas a la ley es la Asociación Salvadoreña de Distribuidores de Vehículos (Asalve). 
Haciendo la revisión del estado de diversificación de los GEFS, así como de los sectores en los que estos compiten, se encontró que un $48 \%$ de estos grupos se diversifican en sectores no transables (figura 1), aunque considerando que la muestra podría ser pequeña con relación al número de grupos empresariales que podrían existir en el país, no podría ser un resultado concluyente como para favorecer lo argumentado por Schneider y Karcher (2012), cuando aseveran que los grupos con frecuencia son fuertes en sectores no competitivos con recursos no transables. Por el contrario, la evidencia encontrada sugiere que los grupos empresariales pueden ser igual de fuertes tanto en sectores de transables como de no transables. Ahora bien, en lo que sí podrían estar más alineados los resultados de este estudio es con relación al grado de flexibilidad y de adaptación de los grupos empresariales, partiendo del hecho de que el $95 \%$ de los GEFS están diversificados, ${ }^{5}$ y que el promedio de sectores en los que compiten es de tres, con un máximo de siete sectores, algunos de ellos más relacionados que otros.

Figura 1. Sectores en los que compiten los GEF presentados en este documento

Fuente: elaboración propia a partir de la información recolectada.

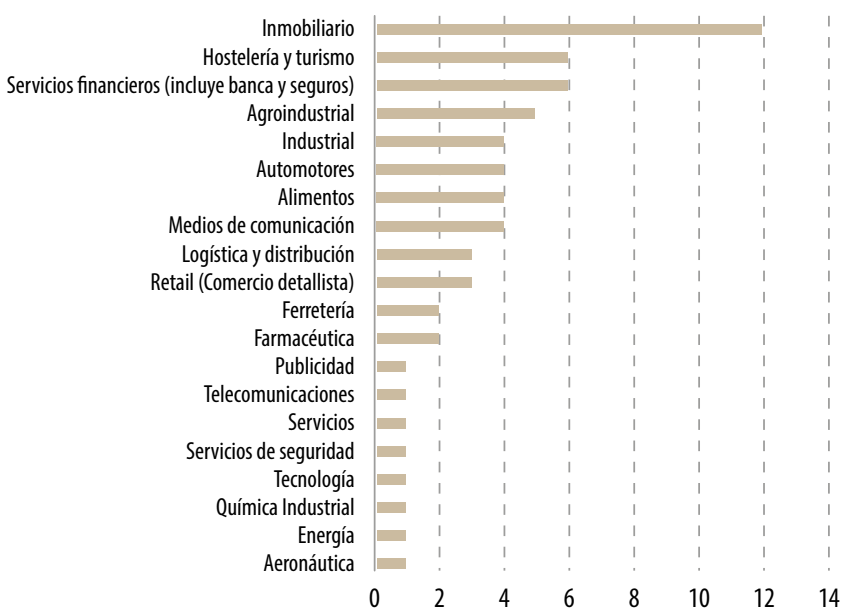

Debe destacarse además que el $50 \%$ de estos grupos tiene inversiones en el sector inmobiliario, lo que confirmaría de alguna manera los argumentos de Valdaliso (1996), cuando expone que los grupos empresariales familiares tienen una tendencia generalizada a diversificar sus negocios, así como a invertir parte del capital acumulado en bienes raíces, obteniendo con ello una renta "segura" y lo que podría considerarse una especie de seguro de fondo de reserva al que acudir en caso de dificultades.

5 El único grupo del que no se encontró evidencia de diversificación hacia otras industrias es Grupo Samix. 
Como ya se expuso, no todos los GEFS acumularon sus riquezas con el cultivo, procesamiento y exportación del café, las privatizaciones de servicios estatales o la compra y venta de instituciones financieras, sino que otros fueron creciendo de manera natural u orgánica —aunque también se vieron favorecidos por medidas proteccionistas-, desarrollando nuevas líneas de productos y diversificándose vertical y horizontalmente de acuerdo a lo que el mercado demandaba, como en los casos de los grupos Calleja, Quality Grains (relacionado con Grupo Q), Campestre, Lorena, Fasani, Vidrí, Freund, Safie y Molina. Algunos de estos grupos nacieron incluso en medio del conflicto armado, como Campestre y Lorena, mientras que otros, como Kriete, Calleja y Salume, se fortalecieron en esta época debido a las oportunidades de negocio y de adquisición de activos a bajo costo que lograron durante el mismo período, ante la salida de conglomerados extranjeros que decidieron no continuar invirtiendo en el país (Contreras, 2019).

El conflicto también generó una nueva situación social para El Salvador, por la migración y el consecuente flujo de remesas de parte de la diáspora salvadoreña. En el primer trimestre de 1991 se recibieron USD 189,1 millones, que pasaron a ser USD 1.705,8 millones en el primer trimestre de 2021, teniendo este año un crecimiento récord de 30,4\%. En total, estas cifras han crecido $802 \%$ desde 1991 (Banco Central de Reserva de El Salvador, 2021 b). Las remesas familiares representan para 2021 entre 15 y $20 \%$ con relación al PIB de El Salvador, por lo que no solo se han convertido en objetivo de los GEFS a través de una amplia oferta de bienes y servicios, sino que también han hecho que El Salvador sea una economía basada en consumo y en servicios.

Por otro lado, el crecimiento de la competencia internacional en el mercado local y los cambios a nivel macro y micro económico han venido mermando desde hace unas cuantas décadas diversas capacidades de competitividad de los GEFS, considerando que el número de multinacionales que compiten en El Salvador es mayor que décadas atrás. De destacarse que el mercado local estaría aún más saturado sino fuese porque El Salvador el segundo país con menor inversión extranjera directa (IED) de Centroamérica, después de Nicaragua; en primer lugar se encuentra Panamá, seguido de Costa Rica (Cepal, 2019). La economía salvadoreña se ha ido abriendo a una mayor incursión de capitales extranjeros, más allá de la mencionada banca, y los flujos de IED se multiplicaron en promedio más de treinta veces en el período 2010-2019, en comparación con el período 1980-1989, aunque hay 
Tabla 5. Flujos de IED en El Salvador de 1980-2019 (en millones de USD)

${ }^{a}$ Los flujos de IED de 1990-1997 no se reflejan en la base de datos económica disponible en el BCR en la fecha de consulta. El informe disponible los presenta como los valores promedio.

${ }^{b}$ Los datos de 2009 y 2020 son suma de flujos de tres trimestres, ya que la información del cuarto trimestre de ese año no se encontraba disponible en la Base de Datos Económica del BCR.

c Para 2020 la suma de los flujos de IED fue de USD 232,95 millones.

\begin{tabular}{|c|c|c|c|c|c|c|c|}
\hline Año & $\begin{array}{c}\text { Flujo de } \\
\text { IED }\end{array}$ & Añ $^{\mathbf{a}}$ & Flujo de IED & Año & Flujo de IED & Año & $\begin{array}{c}\text { Flujo de } \\
\text { IED }\end{array}$ \\
\hline 1980 & 5,90 & 1990 & 15,0 & 2000 & 173,0 & 2010 & $-230,30$ \\
\hline 1981 & $-5,70$ & 1991 & 15,0 & 2001 & 279,0 & 2011 & 218,49 \\
\hline 1982 & $-1,0$ & 1992 & 15,0 & 2002 & 470,0 & 2012 & 466,84 \\
\hline 1983 & 28,10 & 1993 & 15,0 & 2003 & 142,0 & 2013 & 179,21 \\
\hline 1984 & 12,40 & 1994 & 15,0 & 2004 & 363,0 & 2014 & 306,34 \\
\hline 1985 & 12,40 & 1995 & 282,0 & 2005 & 511,0 & 2015 & 396,62 \\
\hline 1986 & 24,10 & 1996 & 282,0 & 2006 & 241,0 & 2016 & 347,43 \\
\hline 1987 & 18,30 & 1997 & 282,0 & 2007 & $1.551,0$ & 2017 & 889,07 \\
\hline 1988 & 17,00 & 1998 & $1.367,6$ & 2008 & 903,0 & 2018 & 826,01 \\
\hline 1989 & 14,40 & 1999 & 216,0 & $2009^{b}$ & 16,35 & 2019 & 662,20 \\
\hline Promedio & 12,59 & - & 250,46 & - & 464,94 & - & 406,19 \\
\hline
\end{tabular}

Lo anterior evidencia un mercado local mucho más saturado de competidores internacionales. De acuerdo con un estudio realizado por Sierra (2021), en su mayoría, el tipo de empresas de IED instaladas en el país son de tipo horizontal puro y de montaje local, cuyas ventas locales les representan más del $90 \%$, lo que significa en el caso de las primeras que son empresas que obtienen todos sus insumos en el país y su producción se vende en un $100 \%$ localmente, mientras que en el caso de la segundas son empresas

6 Incluyendo bancos, aseguradoras, tarjetas de crédito y AFP. 
en las que todos sus insumos provienen de la casa matriz en el extranjero y la producción se vende localmente. Adicional a esto, debe mencionarse que las exportaciones de las empresas de IED han sido mayores a las de las empresas de capital nacional.

Al panorama de un incremento de IED como resultado de la consolidación de la globalización debe sumarse la horizontalidad que la penetración del internet y las nuevas tecnologías están brindado a los empresarios y emprendedores en general, en el sentido en que importar productos ahora es mucho más fácil que hace una o dos décadas, por lo que los márgenes de rentabilidad de cualquier empresa, aunque sea grande, se ven afectados por una mayor atomización de la oferta de bienes a través del comercio en redes sociales y de plataformas de comercio en línea como Amazon, Alibaba y otras plataformas en internet. Por tanto, algunos de los desafíos para los GEFS están relacionados con mantener sus márgenes de rentabilidad, dar sostenibilidad a sus modelos de negocios, buscando también la innovación, y la reinvención y la adaptación constante a los cambios en los hábitos de consumo y compra por canales o medios poco tradicionales. Grupos empresariales como Dutriz y Eserski se han visto amenazados por la incursión de tecnologías disruptivas y la accesibilidad a través de dispositivos móviles, lo que ha incidido en la caída en el consumo de los medios de comunicación tradicionales (TV y prensa).

\section{VINCULACIÓN AL PODER POLÍTICO}

Tal como se ha advertido, el poder económico ha estado íntimamente relacionado con las decisiones políticas, interrelación que se ha mantenido como un condicionante y un factor vivo en la dinámica económica-empresarial actual (Cardenal, 1996; Robles, 2017). Lo anterior puede ser una característica común en los sistemas políticos en Latinoamérica, en el sentido que permiten el acceso de las familias y sus grupos empresariales al cabildeo en el Congreso, así como su influencia en decisiones políticas a través de instrumentos como el financiamiento a los partidos políticos o la participación en instituciones públicas en la que son asignados miembros de la familia o sus empleados. Llegan incluso a sugerir o vetar nombramientos, pues tienen fuerte poder en la decisión de quiénes deben ser los candidatos que los representarán, lo que pareciera ser 
común en Estados Unidos pero menos usual en otros países desarrollados (Schneider \& Karcher, 2012).

Esta dinámica ha sido observada en El Salvador (tabla 6), y aunque parece tener continuidad estaría enfrentando algunos cambios con la reforma electoral para el voto preferencial (o voto por rostro) aprobada en el país desde 2013 para los miembros del Congreso salvadoreño (Araujo, 2017). Si bien esta reforma fragmenta las relaciones internas entre candidatos, también abre la posibilidad de que el sector privado con alto poder - llámense grupos empresariales, sean estos familiares o no- pueda negociar con miembros específicos de los partidos políticos para obtener el favor en alguna legislación vinculante a sus intereses.

La situación política del país ha cambiado considerablemente desde 1989, cuando el Partido ARENA ganó las elecciones y se consolidó en el poder político por veinte años. Desde 1992, cuando se firmaron los Acuerdos de Paz se abrió la posibilidad de que los grupos guerrilleros lograran participar en el poder político a través del Partido Frente Farabundo Martí para la Liberación Nacional (FMLN), el cual pronto ganó representatividad y llegó a convertirse en la segunda fuerza política del país, alcanzando la presidencia en 2009 y durando en el poder una década. En 2019, el candidato Nayib Bukele, del Partido Gran Alianza por la Unidad Nacional (GANA), ganó las elecciones presidenciales, poniendo fin a la polarización y bipartidismo que existió en el país por treinta años (tabla 7).

El alto posicionamiento ganado a través del uso de redes sociales y medios digitales, así como el capital político del ahora presidente Bukele, acuerpó a la mayoría de candidatos del Partido Nuevas Ideas (al que ahora él representaba), para que ganaran como resultado de las últimas elecciones de 2021 con una abrumadora mayoría la Asamblea Legislativa y las alcaldías en todo el territorio nacional (Magaña, 2021).

A partir de 2009, los gobiernos del FMLN y el actual han realizado diversas acciones y una serie de cambios que han afectado a parte de los GEFS. Estos cambios han derivado en una menor capacidad de negociación con los actores políticos, así como en crecientes dificultades para competir y sostener sus márgenes de utilidad. Dentro de estos, los mayores impactos vinieron de la creación de determinadas leyes, aunado al fortalecimiento y apoyo de instituciones que buscaban corregir fallas de mercado. La multa impuesta a Grupo Salume, a través de su empresa Molsa, por aparentemente ponerse de acuerdo con su principal competidor para controlar los precios 
del mercado de harinas, constituye un ejemplo del esfuerzo por sancionar prácticas anticompetitivas, algo que antes de 2009 hubiese sido imposible.

\begin{tabular}{|c|c|}
\hline Período & Figura política al mando del Ejecutivo/ Estructura política representada \\
\hline $1928-1979$ & Presidente/Gobiernos militares \\
\hline $1979-1982$ & Presidente/Juntas Revolucionarias de Gobierno \\
\hline $1982-1984$ & Presidente interino/Civiles \\
\hline $1984-1989$ & Presidente/Partido Demócrata Cristiano \\
\hline $1989-2009$ & Presidente/Partido de Derecha ARENA \\
\hline $2009-2019$ & Presidente/Partido de Izquierda FMLN \\
\hline $2019-2021$ & Presidente/Partido Nuevas Ideas \\
\hline
\end{tabular}

\section{Cambios 0 acciones realizadas por gobiernos del FMLN}

- Eliminación del pago de cuotas voluntarias en los hospitales nacionales.

- Creación de la Ley de Medicamentos y la Dirección Nacional de Medicamentos.

- Creación en 2014 de la Secretaría de Participación, Transparencia y Anticorrupción (STPA).

- Implementación de una política de cielos abiertos para la industria del transporte aéreo.

- Implementación de diversos programas de índole social, como entrega de paquetes escolares, zapatos y uniformes, educación totalmente gratuita, y provisión de alimentos en los centros escolares públicos.

- Mayor impulso a la Defensoría del Consumidor (2005) y a la Superintendencia de Competencia (2006).

- Impulso e implementación de iniciativas empresariales a través del asocio con ALBA y Petróleos de Venezuela, creando empresas en los sectores controlados por los GEFS: Veca Airlines, transporte aéreo; GenteVE, canal de televisión abierta; Tu Solidaria, servicios financieros.

- Y otras: Alba Petróleos, gasolineras; Arrocera El Alba, granos básicos; AlbaTech Green Energy, producción y comercialización de paneles solares.

- Cambios en el Código Electoral para la implementación del voto preferente.

- Reformas en 2017 y 2019 a la Ley de Telecomunicaciones, para endurecer y transparentar los procesos de asignación del espectro.

- Reformas en 2009 y 2019 a la Ley del Sistema de Tarjetas de Crédito.

\section{Cambios 0 acciones realizadas por el gobierno} del Partido Nuevas Ideas

- Dar mayor fuerza a instituciones como el Ministerio de Trabajo y el Ministerio de Hacienda.

Durante la cuarentena de 2021:

- Congelamiento del pago de cuotas de todo tipo de créditos.

- Entrega de dinero en efectivo a familias más vulnerables.

- Entrega de paquetes alimenticios a toda la población.

- Cierre total de fronteras, mucho antes que se detectará el primer caso de COVID-19 en el país.

- Destitución del Fiscal General y de los magistrados de la Corte Suprema de Justicia, el 1 de mayo de 2021, durante la primera sesión plenaria, día en que asumió el nuevo gobierno.
Tabla 6. Resumen de estructuras políticas en el gobierno de turno en El Salvador

Fuente: elaboración propia.

Tabla 7. Principales acciones y cambios políticos implementados durante los gobiernos de El Salvador entre 2009 y 2021 


\section{FINANCIAMIENTO A PARTIDOS POLÍTICOS}

El $48 \%$ de los GEFS presentados en este documento financiaron a partidos políticos en diversos períodos, y no siempre a los de la misma ideología (tabla 8). De igual manera, miembros de las familias propietarias de los grupos Cristiani, Samix y Cassa ocuparon en algún momento de la historia cargos presidenciales, o son descendientes de presidentes; asimismo, ejecutivos y miembros de las familias propietarias ${ }^{7}$ de los grupos Grupo Q (ARENA), Poma (PDC) y Salume (ARENA) ocuparon puestos de gobierno o participaron en candidaturas de partidos políticos (Grupo Calleja y Siman, en ARENA, y Salume en Democracia Salvadoreña).

La influencia de cada grupo empresarial se hace más o menos activa dependiendo de la ideología del partido gobernante en el momento. Entre 2006 y 2018 Grupo Kriete ${ }^{8}$ donó al Partido ARENA cerca de USD 1 millón. En el caso del FMLN, la mayoría de sus financistas son personas naturales o particulares, es decir, no empresas privadas. Sin embargo, en 2009 el principal financista privado del candidato de este partido había sido Nicolás Salume, del Grupo Salume (Vaquerano, 2021). En ese año, el candidato era Mauricio Funes, ahora ex presidente de la República de El Salvador y quien vive exiliado en Nicaragua.

Los empresarios no siempre coinciden en el partido que financian, y varían su preferencia dependiendo de la situación política y económica del momento; destacan entre estos casos Grupo Cassa, Grupo Poma, Grupo Safie, Grupo Agrisal, Grupo De Sola, Grupo Cristiani y Grupo Salaverría, quienes a través de alguna o varias de sus empresas han sufragado a diferentes partidos políticos en períodos específicos (tabla 8).

7 Con cargos de ministros, como en el caso de las familias Quirós (José Ángel Quirós), Poma (Roberto Poma) y Salume (Nicolás Salume), o como candidatos a cargos políticos, en los casos de las familias Simán (Javier Simán, Evelyn Jacir Simán) y Callejas (Carlos Calleja), y en el caso particular de Carmen Aída Lazo, quien se creía representaba los intereses de la familia Poma cuando participó como candidata a vicepresidenta de la república junto a Carlos Calleja.

8 A través de su empresa Taca International. 


\begin{tabular}{|c|c|c|c|c|c|c|c|c|c|}
\hline Año & Partido & $\begin{array}{l}\text { Grupo } \\
\text { Cassa }\end{array}$ & $\begin{array}{l}\text { Grupo } \\
\text { Poma }\end{array}$ & $\begin{array}{l}\text { Grupo } \\
\text { Safie }\end{array}$ & $\begin{array}{l}\text { Grupo } \\
\text { Fasani }\end{array}$ & $\begin{array}{c}\text { Grupo } \\
\text { Agri- } \\
\text { sal }\end{array}$ & $\begin{array}{l}\text { Grupo } \\
\text { De Sola }\end{array}$ & $\begin{array}{l}\text { Grupo } \\
\text { Cristiani }\end{array}$ & $\begin{array}{c}\text { Grupo } \\
\text { Salave- } \\
\text { rría }\end{array}$ \\
\hline \multirow{3}{*}{2006} & ARENA & & & & & 1 & & & \\
\hline & PDC & & & & 1 & & & & \\
\hline & PCN & & 1 & & & & & & \\
\hline 2007 & PDC & & & & 1 & & & & \\
\hline \multirow{2}{*}{2008} & ARENA & & 1 & & & & & & \\
\hline & PCN & & 1 & & & & & & \\
\hline \multirow{3}{*}{2009} & ARENA & 1 & 1 & & & 1 & & & \\
\hline & $P D C$ & & & & 1 & & & & \\
\hline & PCN & 1 & & & & & & & \\
\hline \multirow{3}{*}{2010} & ARENA & & & & & & & & \\
\hline & $P D C$ & & & & 1 & & & & \\
\hline & PCN & & & 1 & & & & & \\
\hline 2011 & PCN & & & 1 & & & & & \\
\hline 2012 & ARENA & 1 & & & & & & & \\
\hline \multirow{2}{*}{2013} & ARENA & 1 & & 1 & & & & 1 & \\
\hline & PDC & & & & 1 & & & & \\
\hline \multirow{3}{*}{2014} & ARENA & 1 & 1 & & & & & 1 & \\
\hline & $P D C$ & 1 & & & 1 & & & & \\
\hline & PCN & 1 & 1 & & & & & & \\
\hline \multirow{3}{*}{2015} & ARENA & 1 & 1 & & & & & 1 & \\
\hline & $P D C$ & & & & 1 & & & & \\
\hline & PCN & & 1 & & & & & & \\
\hline \multirow{2}{*}{2016} & ARENA & & 1 & & & 1 & 1 & & 1 \\
\hline & GANA & & 1 & & & 1 & 1 & 1 & 1 \\
\hline \multirow{3}{*}{2017} & ARENA & 1 & 1 & & & & 1 & & \\
\hline & $P D C$ & 1 & & & & & & & \\
\hline & PCN & 1 & & & & & & & \\
\hline \multicolumn{2}{|c|}{ Total apoyos } & 11 & 11 & 3 & 7 & 4 & 3 & 4 & 2 \\
\hline
\end{tabular}

Tabla 8. Detalle de partidos políticos financiados por los GEFS

Nota: el número 1 solo indica que el grupo donó a través de alguna de sus empresas al partido que se indica en el año de referencia.

Fuente: elaboración propia con información de Secretaría de Participación, Transparencia y Anticorrupción (2006-2018) y Acción Ciudadana.

De la situación histórica anterior podría inferirse que los GEFS gozaron de condiciones microeconómicas relativamente estables hasta 2009, en el sentido en que contaron con reglas de juego un tanto claras y fijas, apoyadas por un esquema político que les favoreció con medidas proteccionistas por mucho tiempo, lo que les permitió, al menos en tanto se sostuvo el modelo agroexportador, e inclusive hasta tres décadas más, disponer de hegemonía como competidores para algunos en sus industrias. Aunque esto es en parte cierto, fue aplicable por un tiempo y en mayor medida para los grupos fundados por la élite cafetalera o las antiguas élites. En otras palabras, no necesariamente aplicó de igual manera para todos los GEFS. 
Ejemplo de esto es que durante el gobierno de trece años del general Maximiliano Hernández Martínez los empresarios locales estuvieron "protegidos" por los decretos del Martinato, a través de los cuales se buscó frenar el avance de empresas industriales estableciendo reglas en contra de las minorías árabes, palestinas, turcas, chinas, libanesas, sirias, egipcias, persas, indias y armenias. Bajo este gobierno, a todas las personas de estas nacionalidades se les prohibió tácitamente instalar almacenes, droguerías, farmacias, tiendas, pulperías, talleres, fábricas industriales, laboratorios químicos y farmacéuticos, industrias agrícolas o agropecuarias (Luna, 1969).

Desde 2019, con la llegada al poder político del presidente Bukele la situación parece que no les será fácil, ya que desde el inicio de su mandato ha tenido una exposición mediática de confrontación con el resto de partidos políticos, al igual que con algunos empresarios de los GEFS, específicamente con empresarios vinculados a las familias propietarias de los grupos Salume y Siman (Villarán, 2019; Villaroel, 2020).

\section{CONCLUSIONES}

Los GEF son actores clave en la economía salvadoreña, al igual que en otras economías alrededor del mundo. En el caso particular, la mayoría de los GEFS que se presentan en este documento gozaron de las ventajas de ser pioneros en sus industrias a finales del siglo XIX e inicios del XX; podría decirse que estrenaron mercados y se convirtieron de alguna manera en los fundadores que sentaron las bases de la economía local. Conforme se fueron desarrollando las economías, se dieron cambios macroeconómicos que exigían apertura de los mercados a nuevos competidores.

Lo anterior trajo también como consecuencia un incremento de los flujos de inversión extranjera directa, y por ende mayor competencia a las empresas locales. Por tanto, los cambios tuvieron efectos tanto positivos como negativos para los grupos empresariales, que hicieron que los GEFS implementaran diversas estrategias para sobrevivir, desde vender activos a especializarse en sus operaciones más rentables, diversificarse ya sea horizontal o verticalmente, hacer inversiones conjuntas o expandirse hacia otros mercados en la región (Bull, 2013; Bull et al., 2014; Cerutti, 2018; Geymonat, 2020; Robles, 2017; Rodriguez-Satizabal, 2020; Segovia, 2005). 
La relación del poder económico con el político continúa evidenciándose, si bien ahora con diferentes instrumentos, por lo que podría inferirse que esta relación nunca dejará de existir, y lo que cambiará serán los actores en alguna de las dos partes, los instrumentos y la calidad de las relaciones. De acuerdo a la evidencia encontrada, el poder político y el económico son interdependientes, porque bajo el sistema electoral actual para asumir el control político se requiere de financiamiento, dinero que no siempre viene del Estado, y que representa una situación mucho más compleja fuera de los alcances y objetivos del estudio que dio origen a este artículo.

Los cambios políticos en El Salvador, y la consecuente creación de nuevas instituciones y leyes, han tratado de corregir fallas de mercado que favorecían a minorías y que daban lugar a medidas de protección, como la operación de monopolios, y a posiciones dominantes, al tiempo que han combatido la falta de equidad o transparencia en la asignación de recursos como el espectro radioeléctrico o el espacio aéreo. Esto pareciera ir en la dirección correcta, en el sentido de generar una sociedad más desarrollada, justa y con condiciones más favorables para las mayorías.

La teoría de que El Salvador era controlado por catorce familias continúa siendo un mito y se requeriría de un estudio más específico para determinarlo, debido a la dificultad histórica de encontrar información fidedigna y oficial respecto a la propiedad de empresas y a sus mecanismos de organización como grupos empresariales. Sin embargo, es necesario señalar la evidencia de un avance en cuanto a la transparencia de datos y a la creación de instituciones que velen por los derechos de ciudadanos y consumidores para el acceso a la información y a condiciones de mercado más justas.

El sector financiero siempre ha sido clave para el desarrollo económico del país, y uno de sus principales protagonistas tanto para la génesis de la diversificación de los cultivos en el país, el financiamiento de grandes y pequeñas empresas, así como para la consolidación y expansión de los grandes grupos empresariales hacia la región centroamericana. Y pese a que la mayoría de los GEFS vendieron sus participaciones en los bancos locales, algunos empresarios salvadoreños están volviendo a invertir en la banca, como en los casos de los fundadores de Banco Azul y Banco Abank. Finalmente, la dinámica de los GEFS no difiere mucho de lo evidenciado por otros autores en Latinoamérica, en el sentido en que se han diversificado hacía más de tres sectores, mantienen relaciones con los políticos y están 
constantemente en la búsqueda de nuevos mercados ante la mayor competencia local, el agotamiento del mercado y los cambios políticos.

\section{REFERENCIAS}

Albiac, M. D. (1998). Los más ricos de El Salvador. Ediciones Böll.

Amaya, J. A. (1995). El papel de los inmigrantes árabes y palestinos en Honduras 1900-1950. Universidad Nacional Autónoma de Honduras.

Araujo, A. C. (2017). Voto preferente en El Salvador: Lecciones aprendidas. Derecho Electoral, 23, 153-169.

Arias, J. S. (2010). Atlas de la pobreza y opulencia en El Salvador. Talleres Gráficos UCA.

Asamblea Legislativa de El Salvador. (2021, mayo 8). Asamblea Legislativa de El Salvador. https://www.asamblea.gob.sv/leyes-decretos

Banco Central de Reserva de El Salvador [BCR]. (2021a). Nacionalización y privatización de la banca salvadoreña, efectividad y lecciones. https://www.bcr.gob.sv/esp/index. php?option=com_k2\&view=item\&id=1289:redibacen\%E2\%80\%9Cnacionalizaci\%C3\%B3n-y-privatizaci\%C3\%B3n-de-labanca-salvadore\%C3\%B1a-efectividad-y-lecciones\%E2\%80\%9D\&Itemid $=168$

Banco Central de Reserva de El Salvador [BCR]. (2021b). Las remesas familiares crecieron 4.8\% en 2020. https://www.bcr.gob.sv/esp/index. php?option=com_k2\&view=item\&id=1537:las-remesas-familiarescrecieron-48-en-2020\&|temid $=168$

Barahona, M. (2019). Elites, redes de poder y régimen político en Honduras. Yoro: Equipo de Reflexión, Investigación y Comunicación, Compañía de Jesús.

Browning, D. (1998). El Salvador, la tierra y el hombre. Concultura.

Bru, L., \& Crespí, R. (2008). Los grupos familiares. Una descripción de los grupos empresariales del Instituto de la Empresa Familiar. Ekonomiaz, 68, 210-229.

Bull, B. (2013). Diversified business groups and transnationalisation of the Salvadorean economy. Journal of Latin American Studies, 45, 265-295. https://doi.org/10.1017/S0022216X13000370 
Bull, B., Castellaci, F., \& Kasahara, Y. (2014). La transnacionalización de los grupos empresariales diversificados y el rostro cambiante de las élites económicas centroamericanas. Anuario de Estudios Centroamericanos, 43, 37-69. https://doi.org/10.15517/aeca. v43i0.31549

Cabrera, A. (2015). Transnacionalización del capital colombiano a Centroamérica. III Jornadas de Pensamiento Latinoamericano. Universidad Federal de Integración Latinoamericana, Foz do Iguaçu.

Cainelli, G., \& lacobucci, D. (2011). Business group and the boundaries of the firm. Emerald Management Decision, 49(9), 1549-1573. https:// doi.org/10.1108/00251741111173989

Calderón, C. M. (2003). Diagnóstico de la inversión extranjera directa en EI Salvador 1998-Junio 2003. BCR.

Cardenal, A. S. (1996). Élites agrarias, estructura económica y transición hacia la democracia en El Salvador. Afers Internacionals, 34-35, 125-147.

Cerutti, M. (2006). Empresas y grupos empresariales en América Latina, España y Portugal. Universidad Autónoma de Nuevo LeónUniversidad de Alicante.

Cerutti, M. (2018). Comportamiento reciente de grupos empresariales del norte de México. Anuario Centro de Estudios Económicos de la Empresa y el Desarrollo, 10, 31-83.

Chudnovsky, D., \& López, A. (1998). Las empresas multinacionales de América Latina: características, evolución y perspectivas. Boletín Informativo Technit, 297, 89-64.

Colindres, E. (1977). Fundamentos económicos de la burguesía salvadoreña. UCA Editores.

Colmenares, S. (1977). Los verdaderos dueños del país, oligarquías y monopolios en Colombia. Fondo Editorial Suramérica.

Colpan, A., Takashi, H., \& Lincoln, J. (2010). Oxford handbook of business groups. Oxford University Press. https://doi.org/10.1093/ oxfordhb/9780199552863.001.0001

Comisión Económica para América Latina y el Caribe [Cepal]. (2019). La inversión extranjera directa en América Latina y el Caribe. Cepal. 
Contreras, C. (2019, agosto 12). Estrategia y negocios. https:// www.estrategiaynegocios.net/especiales/aniversario/ empresaseyn/1309367-521/carlos-calleja-lecciones-de-lapol\%C3\%ADtica-salvadore\%C3\%B1a-al-plano-empresarial

Cuadra, L. (2016). Las élites y los campos de disputa en Nicaragua: una mirada restrospectiva. Península, $X I(1)$, 85-101. https://doi.org/10.1016/j.pnsla.2016.01.004

Dávila, C., Molina, L., Romero, L., \& Rodríguez, B. 2021). “Empresas y grupos empresariales en América Latina, España y Portugal" (coordinado por Mario Cerutti), Monterrey, Universidad Autónoma de Nuevo León-Universidad de Alicante, 2006, 374 páginas. Cuadernos Latinoamericanos de Administración, II(3), 89-91. https://www.redalyc.org/articulo.oa?id=409634346006

Díaz, G. (2016). Oligarquía y élite económica guatemalteca: un análisis de redes sociales. Sociedad y Discurso, 30, 50-70.

Fernández, P., \& Lluch, A. (2015). Familias empresarias y grandes empresas familiares en América Latina y España. Fundación BBVA.

Geymonat, J. (2020). Industrial business groups in a context of deindustrialization. The Uruguayan Case, 1980-2015. Journal of Evolutionary Studies in Business, 5(2), 150-176.

https://doi.org/10.1344/jesb2020.2.j079

Khanna , T., \& Yafeh, Y. (2007). Business Groups in emerging markets: Paragons or parasites? Journal of Economic Literature, XLV, 331-372. https://doi.org/10.1257/jel.45.2.331

Llorca-Jaña, M., Robles, C., Navarrete-Montalvo, J., \& Araya Valenzuela, R. (2017). La agricultura y la élite agraria chilena. Historia, 50(2), 597639. https://doi.org/10.4067/s0717-71942017000200597

Luna, D. (1969). Análisis de una dictadura fascista latinoamericana. La Universidad, 5, 42-130.

Magaña, Y. (2021, mayo 10). Diario El Mundo. https://diario.elmundo.sv/ asi-quedaria-conformada-la-asamblea-2021-2024/

Martinez-Peñate, O. (2013). El Salvador: del conflicto armado a la negociación. Nuevo Enfoque.

Martínez-Peñate, O. (2017). Familia, poder económico y político en El Salvador. Revista ECA, 72(749), 199-230. https://doi.org/10.51378/eca.v72i749.3252 
Paniagua, C. (2002). El bloque empresarial hegemonico salvadoreño. Revista de Estudios Centroamericanos, 57(645-646), 609-694.

Robles, F. (2014). Transformaciones y concentración en grupos de poder económico en Costa Rica (1980-2012). Revista Mexicana de Sociología, 76(1), 37-58.

Robles, F. (2017). Élites en El Salvador: Cambios y continuidades (20002016). Anuario de Estudios Centroamericanos, 43, 99-124. https://doi.org/10.15517/aeca.v43i0.31617

Rodriguez-Satizabal, B. (2020). Pathways from deglobalisation: Colombian business groups, 1950-1985. Journal of Evolutionary Studies in Business, 5(2), 177-214. https://doi.org/10.1344/jesb2020.2.j080

Schneider, B. R. (2009). Hierarchical Market economies and varieties of capitalism in Latin America. Journal of Latin American Studies, 41, 553-575. https://doi.org/10.1017/S0022216X09990186

Schneider, B. R., \& Karcher, S. (2012). La política de las empresas en Latinoamérica:investigando sus estructuras, preferencias e influencia. Apuntes, 39(70), 7-28. https://doi.org/10.21678/apuntes.70.644

Secretaría de Participación, Transparencia y Anticorrupción. (2006-2018). Aportes privados a partidos políticos. GOES.

Secretaría de Participación, Transparencia y Anticorrupción. (2019). Sistema bancario en El Salvador: nacionalización, saneamiento, privatización, e internacionalización. GOES.

Segovia, A. (2005). Integración real y grupos de poder económico en América Central: implicaciones para el desarrollo y la democracia de la región. Fundación Friedrich Ebert.

Serna, M., \& Bottinelli, E. (2018). El poder fáctico de las élites empresariales en la política latinoamericana: Un estudio comparado de 8 países. CLACSO.

Sierra, C. (2021, febrero 18). Caracterización y determinantes de la inversión extranjera directa en El Salvador. https://www.bcr.gob.sv/esp/ index.php?option=com_k2\&view=item\&id=1325:redibacen\%E2\%80\%9Ccaracterizaci\%C3\%B3n-y-determinantesde-la-inversi\%C3\%B3n-extranjera-directa-en-elsalvador\%E2\%80\%9D\&Itemid=168 
Universidad Don Bosco [UDB]. (2021, enero 2). Universidad

Don Bosco. http://www.udb.edu.sv/udb/pagina/

tecnico_mantenimiento_aeronautico

Valdaliso, J. (1996). La historia empresarial en España. Orígenes, desarrollo y controversias respecto a una nueva disciplina. Tandil, Argentina: XV Jornadas de Historia Económica Argentina.

https://doi.org/10.18232/alhe.v4i07.204

Vanoni-Martínez, G., \& Rodríguez-Romero, C. (2017). Los conglomerados empresariales en el Ecuador: un análisis histórico, económico y político. Apuntes del CENES, 36(63), 247-278.

https://doi.org/10.19053/01203053.v36.n63.2017.5456

Vaquerano, R. (2021, febrero 10). El Faro. https://elfaro.net/es/201312/ noticias/13996/La-contradictoria-historia-del-presidente-sobre-elregalo-de-los-\$3-millones.htm

Villarán, J. (2019, abril 30). Diario La Página. https://lapagina.com. sv/nacionales/bukele-fito-salume-deberias-decirle-a-tuempleado-hector-silva-que-deje-de-hacer-sicariato-periodistico/ comment-page-4/

Villaroel, G. (2020, mayo 19). Diario El Mundo. https://diario.elmundo.sv/ bukele-arremete-contra-siman-y-tiende-puentes-a-10-grandesempresarios/

Waxenecker, H. (2017). Élites políticas y económicas en El Salvador: ¿captura de Estado? Ediciones Böll.

Waxenecker, H. (2019). Redes de poder político-económico en Honduras: un análisis post golpe. Fundación Heinrich Böll Stiftung. 